\title{
Innovative Approaches in the Development of Specialized Food Products of Optimized Composition for Patients with Type 2 Diabetes
}

Tutelyan VA ${ }^{1,2}$, Sharafetdinov KhKh ${ }^{1-3}$, Plotnikova OA ${ }^{1}$, Vorobiova IS $^{1}$, Kochetkova AA ${ }^{1}$, Krul ES $^{4}$, Ouwehand AC ${ }^{5}$ and Mendelson GJ ${ }^{*}$

'Federal Research Centre of Nutrition, Biotechnology and Food Safety, Moscow, Russia

2I.M. Sechenov First Moscow State Medical University, Moscow, Russia

${ }^{3}$ Russian Medical Academy of Postgraduate Education, Moscow, Russia

${ }^{4}$ Global Nutrition Innovation, DuPont Nutrition and Health, St.Louis, MO, USA

${ }^{5}$ Active Nutrition, DuPont Nutrition and Health, Sokeritehtaantie 20, 02460 Kantvik, Finland

*Correspondence author: Mendelson GJ, Global Nutrition Innovation, DuPont Nutrition and Health, St.Louis, MO, USA, Tel: 89856286321; E-mail: garry.j.mendelson@dupont.com

Received date: Oct 04, 2016; Accepted date: Oct 21, 2016; Published date: Oct 27, 2016

Copyright: @ 2016 Tutelyan VA et al. This is an open-access article distributed under the terms of the Creative Commons Attribution License, which permits unrestricted use, distribution, and reproduction in any medium, provided the original author and source are credited.

Abstract
Type 2 Diabetes Mellitus is a major medical, social and economic problem, due to the high prevalence and
increasing incidence of the disease with subsequent progression of seriously disabling complications and need for
specialized medical care. Globally, 382 million people have diabetes, and the number of people with the disease is
set to rise beyond 592 million in less than 25 years. Diabetes caused 5.1 million deaths in 2013 . Every six seconds a
person dies from diabetes. Diabetic management is usually targeted at reducing weight, ameliorating glycemic
control and reducing other risk factors that lead to vascular complications. Dietary intervention is considered a
necessary part of the treatment of type 2 diabetes in addition to any glucose-lowering pharmacotherapy. The
development of specialized foodstuffs with predetermined chemical composition is an important objective of clinical
nutrition. This review provides medical and biological rationale for the use of food ingredients with benefits in the
development of optimized food formulations for patients with type 2 diabetes. Key aspects of the development of
specialized food products for patients with type 2 diabetes is to meet the physiological needs of the patient with
foods containing biologically active substances which provide favorable metabolic effects and to be careful to
preserve traditional hedonic qualities of the enriched product, which would be important for compliance and general
product acceptability.

Keywords: Food ingredients; Specialized food products; Type 2 diabetes

\section{Introduction}

Type 2 Diabetes Mellitus (DM) is a major medical, social and economic problem, due to the high prevalence and increasing incidence of the disease and the concomitant progression of seriously disabling complications and need for specialized medical care $[5,16,17,25]$. According to the International Diabetes Federation, currently there are 382 million patients with diabetes [69] in the world with an increase in the rate of incidence: since 1980, the number of patients with Type $2 \mathrm{DM}$ has increased almost three fold [17]. The prevalence of Type $2 \mathrm{DM}$ is higher than the prevalence of all infectious diseases combined, and as a result of this, the World Health Organization (WHO) and the United Nations have identified DM as the most dangerous challenge to the International Community in the twenty-first century [17].

It is predicted that by 2035 , the total number of patients with diabetes will increase by $55 \%$ which corresponds to 592 million people [69]. The social importance of Type $2 \mathrm{DM}$ is defined by grave complications, such as myocardial infarction, apoplexy, gangrene of the lower extremities, nephropathy etc., leading to early disability and a high mortality rate [12,15-17,25,38]. Diabetes caused 501 million deaths in 2013. Every six seconds a person dies from diabetes [69].
Type 2 DM accounts for up to $90 \%$ of all the diabetic cases and is a progressive disease connected with the development of macro- and microvascular complications. It is also characterized by hyperglycemia, which arises from two fundamental pathophysiologic defects: insulin resistance and impaired $\beta$-cell function of the pancreas [3]. Chronic hyperglycemia plays a role in the pathogenesis of diabetic angiopathies, both directly and indirectly, initiating several biochemical processes, which include oxidative stress, excessive formation of glycosylated endproducts, increased diacylglycerol synthesis and others [10].

Indicators of glycemia control are fasting glucose and glycated hemoglobin concentrations, but measuring postprandial glycemia is a more sensitive marker of glycemic control. Hyperglycemia is associated with the risk of vascular complications [4], such as retinopathy, increased intima media thickness of the carotid artery, decreased myocardial blood volume and myocardial blood flow. In this regard, reducing the peak of postprandial glycemia, an independent risk-factor for macro- and microvascular complications in type $2 \mathrm{DM}$, is vital from the point of view of prevention of diabetic complications.

\section{Dietary Intervention and Specialized Foods in Type 2 Diabetes}

Treatment of Type 2 DM is usually targeted at reducing excess body weight, ameliorating glycemic control and reducing other risk factors that lead to vascular complications [3]. Dietary intervention is 
Citation: Tutelyan VA, Sharafetdinov KhKh, Plotnikova OA, Vorobiova IS, Kochetkova AA, et al. (2016) Innovative Approaches in the Development of Specialized Food Products of Optimized Composition for Patients with Type 2 Diabetes. J Diabetes Metab 7: 711. doi: $10.4172 / 2155-6156.1000711$

Page 2 of 8

considered a necessary part of the treatment of type $2 \mathrm{DM}$ in addition to any glucose-lowering pharmacotherapy [2]. In recent years, close attention is being paid to the development of personalized approaches to the management of diseases, taking into account individual parameters of the patient through monitoring of molecular biomarkers [19], including those associated with Type 2 DM [35].

Clinical studies have indicated that the addition of specialized foods with predetermined chemical compositions, such as those having a low glycemic index, in the personalized dietary management of diabetes, is accompanied not only with a recession of the level of basal glycemia and improvement of the lipid metabolism, but it also favors the positive dynamics of indicators of inflammatory status [35]. In addition, specialized foodstuffs, have an advantage compared with standard foods in the complex therapy of the Type 2 DM patient, in achieving optimal glycemic and metabolic control, with marked reduction of the arterial tension, body-mass index, waist and hip circumference, as well as improving physical condition and quality of life [3]. In this regard, the development of specialized foodstuffs with predetermined chemical composition by the enrichment, elimination, modification or replacement of certain macro- and/or micronutrients is an important objective of clinical nutrition intended to correct the chronic hyperglycemia and metabolic disturbances which underlie Type 2 DM.

\section{Dietary trend in specialized foods development}

Carbohydrate: It is generally accepted that the amount of carbohydrate and differences in the chemical structure of carbohydrates contained in foodstuffs, especially starch and sucrose, are the main determinants of the postprandial glycemic response $[13,78,83]$. Starch is a polymer of glucose (homopolysaccharide), consisting of two fractions: amylose and amylopectin [78]. Amylose has a predominantly linear structure in which glucose residues are fixed with $\alpha-\mathrm{D}-(1 \rightarrow 4)$ bonds.

Amylopectin is a polymer with a highly ramified chain (average chain length of 20-25 glucose residues) with $\alpha-D-(1 \rightarrow 4)$ and $\alpha-D-(1 \rightarrow 6)$ glycoside bonds [55]. The ratio of the two-part fractions of the starch (amylose and amylopectin) varies in different carbohydrate-containing foods, but usually it is the amylose that is the minimal component: most cereal starches contain $15-25 \%$ of amylose, and the rate of digestion of the starch depends on the ratio of amylose and amylopectin in its structure [78]. In recent years, the range of foodstuffs in which modified starches, obtained by physical and chemical methods from native vegetable starches or starchy foods are used, have been expanded.

By their chemical nature both modified and native starches are homoglucans and are mainly represented as a mixture of amylose and amylopectin. The digestibility of modified starches is affected by its accessibility to glycolytic enzymes, which depends on the chemical composition of the starch, the spatial structure of the molecules of modified starches, as well as on its water-holding and gel-forming properties [14]. The chemical modification of starch, which yields stabilized and cross-linked starches, affects its accessibility to aamylase and determines a great deal the resistance to decay of $a-D$ $(1 \rightarrow 4)$-glucans links throughout the length of the chain, which slows the hydrolysis and the entry of the glucose into the blood as the end product of starch hydrolysis. Thus, one of the methods to optimize glycemic control of patients with Type $2 \mathrm{DM}$ is the use of modified starches in the composition of specialized foodstuffs as food ingredients, by affecting the accessibility of glycolytic enzymes, reducing the postprandial glycemic response and hence, reducing the glycemic index of the carbohydrate-containing product.

One of the basic requirements in the management of Type $2 \mathrm{DM}$, is to limit simple carbohydrates which are the rapidly absorbed refined mono- and disaccharides [2,3]. As is well known, mono- and disaccharides, contained in the food, play a vital part in the modulation of the post-prandial glycemic reaction in diabetic patients, however, differences in both the absorption and the metabolism rates of distinct mono- and disaccharides show variations in the degree of increase of the postprandial glycemia after consumption [78]. The most rapid and sharp increase in the level of glucose of the blood is observed after consumption of glucose or sucrose. Fructose is absorbed more slowly, being metabolized faster in the liver, and as studies show, the consumption of fructose results in a significantly smaller increase of post-prandial glycemia of patients with Type $2 \mathrm{DM}$, compared with the consumption of the same amounts of glucose or saccharose [43]. Several meta-analyses of controlled studies have shown that the consumption of fructose at the expense of other simple carbohydrates is accompanied by a decrease of the content of glycated protein (glycated albumin and $\mathrm{HbAlc}$ ) without any significant effect on the fasting level of the glucose and insulin $[56,75]$. The absorption of fructose in the intestines increases if it is consumed together with other sugars or starch [55,78]. Consumption of fructose leads to the formation of the fructose-one-phosphate which activates hepatic glucokinase, and consequently increases the consumption of glucose in the liver $[73,78]$. It should be noted that the formation of the fructoseone-phosphate requires a large amount of ATP, so an excess of fructose in the food, can lead to a decrease in the hepatic content of ATP and intracellular inorganic phosphorus. Therefore, the consumption of fructose as "an alternative" of sucrose must be within reasonable limits to prevent adverse metabolic consequences [8].

Finally, there is evidence that fructose can indirectly affect glucosedependent insulin secretion, facilitating the release of glucagon-like peptide-1 (GLP-1) by the enteroendocrine L-cells of the small intestines [73]. GLP-1 possesses incretin activity, meaning it stimulates insulin release by the pancreas. There is significant research currently aimed at the creation of analogues of GLP-1 to treat Type 2 DM [18].

In recent years, the development and production of foodstuffs containing sugar substitutes (sugar alcohols such as polyols: sorbitol (E420), lactitol (E966), xylitol (E967), maltitol (E965), etc.), has been intensively progressing, particularly in foods formulated for the diets of diabetic patients [23]. These sugar alcohols are less well absorbed in the intestine and therefore have a lower caloric value than refined sugars such as sucrose. A number of studies have shown that the consumption of polyols by healthy individuals and DM patients in a quantity of $50 \mathrm{~g}$ is accompanied by lower postprandial glycemic response than the consumption of fructose, sucrose or glucose [61]. A less distinct increase of the postprandial glucose of Type 2 DM patients was noted when the consumption of sorbitol and isomalt was within the limits of $30 \mathrm{~g}$, compared with the consumption of corn syrup in an equivalent amount [43]. An excessive consumption of polyols, particularly sorbitol, has an adverse laxative effect in the gastrointestinal tract, causing diarrhea $[47,61]$. Therefore, while levels of xylitol, sorbitol and erythritol are well tolerated at $15 \mathrm{~g}$ per serving, the upper acceptable consumption level for xylitol and sorbitol is 40 $\mathrm{g} / \mathrm{a}$ day and for erythritol is $45 \mathrm{~g} / \mathrm{a}$ day [26].

Other widely used compounds to reduce the energy value of foodstuffs include natural and synthetic sweeteners. On a weight basis, synthetic sweeteners are lower in calories and significantly exceed the 
Citation: Tutelyan VA, Sharafetdinov KhKh, Plotnikova OA, Vorobiova IS, Kochetkova AA, et al. (2016) Innovative Approaches in the Development of Specialized Food Products of Optimized Composition for Patients with Type 2 Diabetes. J Diabetes Metab 7: 711. doi: $10.4172 / 2155-6156.1000711$

Page 3 of 8

sweetness of sucrose. Such sweeteners are aspartame (E951), saccharin (E954), cyclamate (E952), acesulfame K (E950) and sucralose (E955). Previous studies have shown the absence of a hyperglycemic and insulinemic effect after the consumption of aspartame and saccharin by type 2 diabetics [53]. In recent years, both scientific and consumer interest was stimulated by the data on the relatively new sweetener neoaspartame (neotame E961), which is different from the aspartame with significantly greater sweetness, greater thermal stability and chemical resistance, and does not affect the level postprandial glycemia of patients with type $2 \mathrm{DM}[11]$.

Another approach by the food industry to impart the usual sweet taste to specialized foodstuffs with fewer calories than sucrose is the use of the natural sweetener stevioside (E960), which is produced by aqueous or aqueous-alcoholic extraction out of perennials of the aster family Stevia rebaudiana Bertoni [34]. In Russia, stevia is known as a "honey grass". The plant is cultivated in Paraguay, Argentina and other countries of South America, South-East Asia and Japan. The sweet compounds of stevia leaves are diterpene glycosides, derivatives of steviol. The main compounds are stevioside, rebaudioside A, B, C and D. The sweetest compound is rebaudioside A (degree of sweetness 350-450 compared to sucrose which is set at 100) [23]. A characteristic property of stevioside is the bitter aftertaste which can be eliminated by intermolecular trans-glycosylation under the action of some enzymes [1]. Stevioside promotes normalization of glucose in the blood and blood pressure and has insulinotropic and glucagon-reducing action $[71,72]$. In recent years, the enzymatically prepared glycosylated stevioside has been used commercially for food production [24].

The maximum allowable content of these substitute sugars in foodstuffs is fixed by Technical regulations of the Customs Union "Safety Requirements for food additives, flavorings and technological supporting equipments" (TR CU 029/2012) [39].

\section{Dietary fibers}

A deficit in dietary fibers (fiber) is known to be associated with an increased risk of diseases such as colon [large intestine] cancer, irritable bowel syndrome, hypomotor dyskinesia of the large intestine with constipation syndrome, cholelithiasis, Type $2 \mathrm{DM}$, atherosclerosis, coronary heart disease (CHD), etc. As a result, specialized foodstuffs, containing both soluble and insoluble fiber have been widely use in recent years for the correction of metabolic disturbances $[6,7,41]$. According to the definition of the American Association of Cereal Chemists $[20,46,89]$, edible parts of plants or kindred carbohydrates, resistant to digestion and adsorption in the small intestine of man, and completely or partially fermentable in the large intestine, are referred to as fiber. Fibers are polysaccharides, consisting of ten or more monomeric residues, resistant to hydrolysis by the enzymes of the small intestine [41] and can include oligo- and disaccharides, having in its composition from 2 to 9 monomer units. [Jones JM (2014) CODEX-aligned dietary fiber definations help to bridge the 'fiber gap', Nutr J 13.14] In Russia, physiological requirement for fiber is $20 \mathrm{~g} /$ day for adults and 15-20 g/day for children [27].

Fibers have beneficial physiological and metabolic effects $[6,7,20,41,48,63,78,93]$, which include: moderation of gastric emptying by polysaccharides with high viscosity, namely soluble fibers such as pectin, guar gum, etc. increase of the speed of transit of intestinal contents of the colon when wheat bran, vegetables and fruits are added to the diet increasing the volume of fecal mass and frequency of bowel movements; in this regard, hemicellulose and lignin perform better than other types of fiber to increase the fecal mass, speed up the transit through the gastrointestinal tract and improve the motor-evacuation function of the intestines and gallbladder.

Prebiotic effect: Some polysaccharide fibers (inulin, gum Arabic) and oligosaccharides (oligofructose) contribute to the growth and development of the normal intestinal microbiota, including bifidobacteria, which is accompanied by decrease of $\mathrm{pH}$ of the intestinal lumen, inhibition of the bacterial formation of potential carcinogens, increase of butyrate production and protection of enterocytes from malignant degeneration, etc.

Hypocholesterolemic effect: Associated with the ability of fiber to bind, increase the excretion and accelerate the metabolism and excretion of bile acids, as well as to slow the absorption of cholesterol in the small intestine, to reduce the absorption of lipids by increasing their fecal excretion, and to inhibit cholesterol synthesis in the liver through the action of short-chain fatty acids produced during the fermentation of soluble fiber in the colon;

Hypoglycemic effect: Lowering of the postprandial glucose response by soluble fiber (pectin, gums) resulting from the slowing of stomach emptying, by decreasing the accessibility of starch to digestive enzymes, and by decreasing the absorption of glucose in the small intestine.

Numerous studies show that the consumption of soluble fiber is accompanied by a reduction of postprandial glucose- and insulin levels in the blood of both healthy individuals or patients with type 1 and 2 DM $[48,61]$. Four randomized controlled studies which, included 116 patients with type $2 \mathrm{DM}$, demonstrated an improvement of glycemic control and insulin sensitivity of tissues after 10 weeks of consumption of soluble fibers, such as psyllium and guar gum [48]. A meta-analysis of 67 controlled clinical studies that included healthy and diabetic subjects showed that diets with a high content of soluble fiber reduced the total cholesterol and the LDL [low density lipoprotein] cholesterol without a significant effect on the level of triglycerides in the blood [52]. The consumption of guar gum powder, pectin and $\beta$-glucan in the amount of 6.6-30 g/a day, 2.2-9 g/a day and 1.5-13 g/a day, respectively, was associated with a reduction of the LDL cholesterol in the blood on average $7.3 \%, 13.7 \%$ and $8.0 \%$ respectively [52].

Soy cotyledon fiber has been shown in acute glucose tolerance tests to reduce the postprandial glucose response compared to cellulose [95], an isoenergetic liquid meal [96] or an isoenergetic noodle meal without added fiber [97] in subjects with Type 2 DM.

A novel fiber, polydextrose, is produced through acid condensation of glucose and is a randomly linked oligosaccharide. The mean degree of polymerization is 12 . The linkages are both $\alpha$ and $\beta$ and consist of $1 \rightarrow 2,1 \rightarrow 3$ and $1 \rightarrow 4$ but $1 \rightarrow 6$ predominate. The molecule is not digested by host enzymes and is not absorbed, thus qualifying as a dietary fiber [98]. Through its complexity, the molecule is also only slowly degraded by the intestinal microbiota and part of the molecule is excreted in the feces [99]. The energy provided by polydextrose is thus only from the metabolites produced by the gradual and limited fermentation of the molecule and thereby contributes with only $1 \mathrm{kcal} / \mathrm{g}[100]$.

Type $2 \mathrm{DM}$ is often associated with overweight and is one of the key characteristics of metabolic syndrome. Polydextrose can be beneficial on several different levels from the point of view of Type-2-diabetes mellitus. As polydextrose is not degraded by host enzymes, it does not lead to an increase in blood glucose levels [101]. Furthermore, it is used as a bulking agent to replace sugar [102]; as mentioned above it is well suited for this due to it is small energy contribution. Polydextrose 
Citation: Tutelyan VA, Sharafetdinov KhKh, Plotnikova OA, Vorobiova IS, Kochetkova AA, et al. (2016) Innovative Approaches in the Development of Specialized Food Products of Optimized Composition for Patients with Type 2 Diabetes. J Diabetes Metab 7: 711. doi: $10.4172 / 2155-6156.1000711$

Page 4 of 8

can influence the effect of sugar on the body in two ways. For instance, the consumption of dried cranberries with less sugar and $10 \mathrm{~g}$ added polydextrose led to lower increases in both blood glucose and insulin compared to dried cranberries with added sugar in subjects with Type 2 DM [103]. Similar observations have been made with overweight subjects [104]. A recent animal study with mice on a high fat diet has shown that supplementing sitagliptin (a dipeptidyl peptidase-4 (DPP4) inhibitor used in treatment in Type $2 \mathrm{DM}$ ), with polydextrose increased the efficacy of the drug alone leading to improved blood glucose levels [105]. Upon replacing sucrose with a polydextrose:lactitol blend, in the form of chocolate, a reduction in the post-prandial lipidemic response has been reported in rats [106]. Nevertheless, consumption of polydextrose has been observed to lead to higher levels of non-esterified fatty acids and concomitant increased fat oxidation in men and women, probably due to the lower caloric content of the polydextrose containing products [104]. Polydextrose has also been reported to reduce LDL serum cholesterol levels in hypercholesterolemic subjects [107]; but only at the highest dose tested (30 g/day). In relation to metabolic syndrome, weight management is an important topic. Sugar replacement and caloric reduction of food may play a role here. In this regard, polydextrose can support weight management. When provided as a mid-morning snack, polydextrose can reduce subjective feelings of appetite, satiety and satiation [108]. Indeed, consumption of polydextrose has been shown to lead to a dose-dependent reduction in energy intake in a subsequent meal. Importantly, no compensation occurs during the subsequent meal, resulting in an overall smaller energy intake over the day [109].

To summarize, polydextrose has many potential benefits for patients with Type $2 \mathrm{DM}$; replacement of sugar, reduced blood glucose and inulin response; improved efficacy of anti-Type $2 \mathrm{DM}$ medication and improved blood lipid profiles. In addition, polydextrose may help in weight maintenance which also may contribute to management of Type 2 diabetes.

Consumption of fiber in general is accompanied by a decrease in systolic and diastolic blood pressure of hypertensive persons by an average of $6.0 \mathrm{~mm} \mathrm{Hg}$ and $4.2 \mathrm{~mm} \mathrm{Hg}$, respectively, as shown in a meta-analysis conducted by Whelton et al. [92]. Thus, the inclusion of fiber in the composition of specialized foodstuffs as a functional ingredient seems promising in order to optimize dietary management of a variety of symptoms associated with type $2 \mathrm{DM}$. In this regard, the main objective is to satisfy the fiber requirements of a patient while meeting the traditional quality and taste experience of the enriched product. This can be accomplished by selecting beneficial fibers, based on their physico-chemical and food functionality parameters to increase the probability of overcoming any technological hurdles to successfully produce the enriched product [20].

\section{Protein}

Among the various factors influencing postprandial glycemic response, the number and qualitative composition of the protein in the consumed food has a significant importance. It is known that the protein loading has an effect on the postprandial glycemia, and leads to increased concentrations of insulin in the blood [61,62]. This effect is more evident in patients with Type $2 \mathrm{DM}$ than persons not suffering from diabetes.

A number of studies on the impact of protein-enriched mixed foodstuffs on glycemic and insulin response indicates that the addition of protein to a carbohydrate load or a mixed meal in the amount of $16-50 \mathrm{~g}$, is accompanied not only by increased insulin secretion, but also helps reduce the postprandial glycemia of both healthy individuals and patients with DM [83]. Addition of protein and fiber from lupin or soy to a standard carbohydrate load reduced the glycemia in Type 2 DM subjects, indicating a possible additive role of the two macronutrients in maintaining glycemic control [110]. The protein demand of diabetic patients under conditions of chronic hyperglycemia is believed to be somewhat larger than the recommended quantity of protein suggested for healthy persons [61]. Moreover, subjects in hospitals or institutions may be exposed to low protein food rations, low digestibility of the protein from food or a reduction of total food intake which then disturbs the dynamic balance of protein metabolism, shifting it to towards the point of net breakdown of the body's own proteins which results in muscle wasting [29]. Therefore, taking into account the critical role of food proteins, including their insulinotropic action, when developing specialized foodstuffs for patients with Type $2 \mathrm{DM}$, it is very important to ensure a balance and optimize the dietary protein composition with the introduction of proteins of high nutritional quality, containing all essential amino acids, and with a high digestibility.

\section{Lipids}

One of the approaches to improve the effectiveness of personalized dietary interventions to normalize the defective lipid metabolism in Type $2 \mathrm{DM}$ to reduce the risk of vascular complications, is the modification of the lipid composition of a diet. In particular, the inclusion of Monounsaturated Fatty Acids (MUFA) and Polyunsaturated Fatty Acids (PUFA) of the omega- 3 class into the specialized foodstuffs. MUFA are characterized by the presence of one double bond (unsaturated) which is relatively resistant to oxidation and is the major fatty acid in in olive oil (the main representative is the oleic acid C18:1). MUFAs are considered as a dietary fatty acid component that has little effect on the level of lipids in the blood [60].

Epidemiological studies have established a negative correlation between the content of MUFA or the ratio of MUFA/total fat in diet and mortality from coronary heart disease (CHD) $[64,70]$. MUFAs are associated coated with a lower levels of total cholesterol (TC) and LDL cholesterol in CHD patients, and increases of HDL cholesterol in the serum with the augmentation of the amount of MUFA in the diet up to $20 \%$ of the total caloric intake $[31,49,68,86]$. There is an evidence of improved glycemic control (decrease of the basal glycemia, post-food peak of the glycemia, daily glycosuria) and insulin sensitivity of tissues, increasing the hypotensive effect of the diet in patients with type 2 diabetes with higher content in the MUFA diet $[44,68]$. Diets with a high content of MUFAs are believed not to increase body mass and are more acceptable for patients with obesity, compared to low-fat diets [87]. Substitution of dietary carbohydrates with MUFAs may be associated with lower mortality risk and weight reduction in patients with type 2 DM [111]. Biotechnology efforts have generated cultivars capable of providing sustainable sources of MUFAs that may make these oils more widely available and affordable in the future [112].

Polyunsaturated fatty acids (PUFAs) comprise a series of fatty acids with multiple double bonds and include several essential fatty acids (linoleic (18:2 n-6) and linolenic (18:3 n-3)) that are indispensable factors of nutrition and their deficiency causes a grave disruption in the structure and function of cell membranes, intracellular metabolism and biosynthesis of eicosanoids (prostaglandins, leukotrienes, thromboxanes) [78]. The main $\omega$-3 PUFAs are $\alpha$-linolenic acid (C18:3 $\mathrm{n}$-3) contained in some vegetable oils (linseed, soybean, rapeseed, mustard, etc.), nuts, green vegetables, and products of elongation 
Citation: Tutelyan VA, Sharafetdinov KhKh, Plotnikova OA, Vorobiova IS, Kochetkova AA, et al. (2016) Innovative Approaches in the Development of Specialized Food Products of Optimized Composition for Patients with Type 2 Diabetes. J Diabetes Metab 7: 711. doi: $10.4172 / 2155-6156.1000711$

Page 5 of 8

which are - eicosapentaenoic and docosahexaenoic acid (C20:5 $\omega-3$ and C22:6 $\omega-3)$, present mainly in saltwater fish fat, mammals, mollusks, marine plants and phytoplankton. Numerous experimental and clinical studies have demonstrated an extensive therapeutic effect of $\omega-3$ PUFA due to their hypolipidemic, hypotensive, thrombolytic, anti-inflammatory, immune enhancing action $[30,32,58,76]$. The results of clinical studies demonstrate the advisability of including MUFA and $\omega-3$ PUFA in the composition of specialized foodstuffs in order to optimize the fatty acid composition and thereby increase the diet's efficacy to ameliorate metabolic disorders and risk factors for cardiovascular complications in Type $2 \mathrm{DM}$.

\section{Micronutrients}

The development of new specialized foodstuffs for patients with Type $2 \mathrm{DM}$, requires utmost consideration of ensuring the adequate content and optimal balance of vitamins, minerals and trace elements. Type $2 \mathrm{DM}$ is associated with deficiency of several micronutrients $[47,80,81,94]$ and is accompanied by a disturbance of processes of utilization of glucose and impairment of insulin secretion, and activation of free radical oxidation of lipids. At any stage in the progression of Type $2 \mathrm{DM}$, and especially after the long-term and serious complications of the disease, the metabolic processing of watersoluble vitamins is disturbed [22]. Folic acid, B6 and B12 vitamins are cofactors that are required for the metabolic conversion of homocysteine. Reduced level of these cofactors may cause the hyperhomocysteinemia [88]. High concentrations of homocysteine in patients with Type $2 \mathrm{DM}$ contribute to the development of micro- and macro-angiopathies and hypertension $[33,54,77,79]$. The deficiency of $\mathrm{B} 1$ vitamin (thiamine) associated with Type $2 \mathrm{DM}$, breaks the coupling of glycolysis with the tricarboxylic acid cycle, inhibits glucose utilization and reduces tolerance to this carbohydrate [84]. The lack of vitamin B2 (riboflavin) is accompanied by impaired fat oxidation and decreased mitochondrial energy production [59]. Any deficiency of ascorbic acid, vitamin D, E and carotenoids, contributes to the development of insulin-resistance and atherosclerotic vascular changes with the type 2 diabetes $[9,21,57,65,91]$, while vitamin $\mathrm{D}$ deficiency is associated with development of complications such as diabetic nephropathy and diabetic foot $[74,90]$. Often a lack of vitamins is combined with a lack of several minerals [45,51,61,80,81], aggravating the course of Type $2 \mathrm{DM}$. Chromium deficiency is accompanied by the impaired metabolism of glucose and lipids, decreased number of insulin receptors and development of insulin resistance [80,94]. A number of studies have shown that the use of chromium and Baker's yeast containing chromium, is accompanied by a significant reduction of $\mathrm{HbA1C}$, basal and postprandial glycemia and insulinemia and improvement of lipid blood parameters in patients with Type 2 DM $[42,61,94]$. Zinc deficiency is thought to lead to impaired glucose tolerance, but its role in the pathogenesis of Type $2 \mathrm{DM}$ still remains unproven $[80,81]$. There is evidence of a reduced supply of selenium in patients with the Type $2 \mathrm{DM}$, which is an essential trace mineral, a necessary cofactor of the enzyme glutathione peroxidase (GP), and which plays an important role in providing an antioxidant protection of the organism [36]. Providing the optimal selenium in the dietary intervention resulted in a trend towards increased activity of erythrocyte GP and reduced level of products of lipid peroxidation [37].

An insufficient supply of the body with biologically active minor food components, many of which may offer chemoprotection or chemoprevention, is one of the causes of decreases in nonspecific resistance to adverse environmental factors of chemical and biological nature (maladaptation), formation of immunodeficiency states, dysfunction of the antioxidant defense, etc. [40]. The natural chemopreventive compounds include different groups of flavonoids (flavonols and their glycosides - quercetin, kaempferol, rutin, etc.; flavones - luteolin, apigenin, etc. isoflavones and their glycosides daidzein, genistein, etc.; flavanone - naringenin, hesperidin, etc.; dihydroflavonols, proantocianidinas, catechins and others) $[78,85]$. Their high biological activity is due to the presence of antioxidant properties, particularly the ability to inhibit LDL oxidation, to form chelate complexes with metal ions and to bind free radicals [78].

Moreover, flavonoids can suppress the formation and release of factors that promote inflammation and the destruction of tissues, such as tumor necrosis factor, leukotrienes, and prostaglandins. According to Nedosugova et al. [28], the application of the dihydroquercetin in a daily dose of $120 \mathrm{mg}$ was accompanied by a decrease in basal and induced malondialdehyde, increased activity of superoxide dismutase and catalase in erythrocytes in patients with Type $2 \mathrm{DM}$ presenting with pre-proliferative retinopathy and pre-clinical stages of nephropathy. Some data have clearly demonstrated that polyphenolic compounds in green tea, particularly catechins, flavonols, and others, have a distinct antioxidant activity, and improve vascular endothelial function. They also exert an antithrombotic effect and have a beneficial effect on carbohydrate and lipid metabolism and reduce body mass $[50,66,67,82]$. According to Nagao et al. [82], the daily intake of green tea extract, containing $690 \mathrm{mg}$ catechins, by healthy men for 12 weeks, was accompanied by a significant reduction of body weight and fat mass, compared with the daily consumption of $22 \mathrm{mg}$ of catechins (control). The ingestion of high levels of catechins was also positively correlated with a significant decrease in the content of MDA-modified low density lipoproteins in the serum [82].

\section{Conclusion}

Evidence-based nutrition principles and recommendations for the treatment of diabetes and related complications have been developed and implemented in many developed countries $[47,61]$.

The nutritional therapy recommendations for diabetes management focus on targeting lifestyle changes to achieve modest weight-loss and weight-maintenance. It becomes apparent that there is an important role of specialized food products with a given chemical composition for the treatment of diabetes and related complications. There is no doubt that the special nutritional food products should not only meet the physiological needs of the body for nutrients and energy, but should also possess preventive and therapeutic bioactivities to help normalize or reduce dysfunctional metabolic processes in the body.

The most important objectives for the development of specialized foodstuffs for patients with Type $2 \mathrm{DM}$, are to meet the physiological needs of the patient with food that delivers biologically active substances, while preserving the traditional quality and enjoyment of the enriched product. This may require adapting the formulation of the product for the purpose of adjusting for possible hedonic or physical properties of the foods caused by the introduction of functional ingredients. The solution of these complex issues, ensuring high quality and safety of specialized food products with optimized composition and form for patients with Type $2 \mathrm{DM}$, provides new opportunities for multifactorial management of the Type $2 \mathrm{DM}$ to reduce the risk of vascular complications and improve the quality of life of patients [3]. 
Citation: Tutelyan VA, Sharafetdinov KhKh, Plotnikova OA, Vorobiova IS, Kochetkova AA, et al. (2016) Innovative Approaches in the Development of Specialized Food Products of Optimized Composition for Patients with Type 2 Diabetes. J Diabetes Metab 7: 711. doi: $10.4172 / 2155-6156.1000711$

Page 6 of 8

\section{Claim}

Russian part of the study was performed at the expense of the grant provided by the Russian Scientific Foundation (project number 14-36-00041)

\section{References}

1. Abelian VA (2001) Cyclodextrins: production and usage - Yerevan. Van Aryan 20: 10-16.

2. Dedov MV, Shestakova W (2013) Algorithms of Specialized Medical Care for Patients with Diabetes Mellitus. Ministry of Health RDA FSBI 21: 120.

3. Ametov AS (2013) Type 2 Diabetes Mellitus. Problems and Solutions. Moscow: GEOTAR-Media 1032.

4. Ametov AS, Melnik AV (2007) Managing diabetes mellitus: role of postprandial hyperglycemia and ways of its correction. RMJ 15: 2053-2058.

5. Ametov AS, Solovyova OL (2011) Cardiovascular complications in diabetes mellitus: pathogenesis and ways of correction. RMJ 27: 1694.

6. Bagarin EK (2006) Content dietary fiber in nutrition products of vegetative origin. Vopr Pitan 75: 42-44.

7. Bagarin EK, Zhminchenko VM (2007) Dietary fiber: terms and definition. Vopr Pitan 76: 10-14.

8. Balabolkin MI (1994) Diabetes Mellitus. Moscow: Medicina 3: 384.

9. Balabolkin MI, Klebanova EM, Kreminskaya VM (2007) Role of vitamins and micronutrients in sustaining compensation of carbohydrate metabolism in patients with diabetes mellitus. Klinicheskaia Endokrinologiia 1: 1-3.

10. Balabolkin MI, Klebanova EM, Kreminskaya VM (2005) Treatment of Diabetes Mellitus and its Complications: Study Guide. Moscow: Medicina 5: 509-512.

11. Baturina VA, Sharafetdinov KH, Meshcheriakova VA (2004) Influence of a new sweetener neoaspartam on blood glucose in patients with diabetes mellitus type 2. Voprosy Pitaniia 73: 18-20.

12. Biryukova EV (2010) Diabetes mellitus and cardiovascular complications: is it possible to break the icious circle? RMJ 18: 904-906.

13. Gapparov MM, Virovets OA, Antonova ZhV (1997) Chronological parameters of carbohydrate utilization in the body. Vopr Pitan 2: 3-9.

14. Gapparov MM, Sokolov AI, Martynova EA, Kulikova OS, Bessonov VV, et al. (2007) [Physical, chemical and biological properties of food modified starches]. Vopr Pitan 76: 15-20.

15. Dedov II, Shestakova MV, Suntsov YuI (2008) Diabetes Mellitus in Russia: Problems and Solutions. Moscow1: 3-6.

16. Dedov II (2010) Diabetes mellitus: development of technologies in diagnosis, treatment and prevention. Saharhii Diabet 3: 6-13.

17. Dedov II (2012) Diabetes mellitus - a dangerous challenge to the world community. Vestnik Rossiiskoi Akademii Meditsinskih Nauk 1: 7-13.

18. Dedov II, Shestakova MV (2010) Incretins: a New Milestone in the Treatment of Diabetes Mellitus Type 2. Practical Guide for Physicians. Moscow: Dipak 22: 92.

19. Dedov II, Tyulpakov AN, Chekhonin VP (2012) Personalized medicine: current status and perspectives.Vestnik Rossiiskoi Akademii Meditsinskih Nauk 12: 4-12.

20. Ipatova LG, Kochetkova AA, Shubin OG (2004) Physiological and technological aspects of dietary fiber usage Pischevie Ingredienti. Syrio i Dobavki 2: 14-16.

21. Karonova TL, Miheeva EP, Krasilnikova EI (2012) Vitamin D deficiency a risk factor for obesity and diabetes mellitus type 2 in women of reproductive age Arterialnaya Gipertenziia 1: 25-32.

22. Kodentsova VM, Vrzhesinskaia OA, Sokol'nikov AA (2012) Food fortified with vitamins: the history and perspectives. Vopr Pitan 81: 66-78.

23. Korpachyov VV (2004) Sugar and Sugar Substitutes. Kiev: Kniga plus 3: 305-320.
24. Kostina VV (2003) Use of glycosylated stevioside in production of dairy beverages. Pischevaya Promishlennost 12: 48-49.

25. Maslova OV, Suntsov I (2011) Epidemiology of diabetes mellitus and microvascular complications. Saharnii Diabet 3: 6-12.

26. Sharma A (2004) Guidelines (methodological recommendations) Recommended consumption levels of food and biologically active components. Moscow 3: 36.

27. Guidelines (methodological recommendations) (2005) MR 2.3.1.24.32-08. Norms of physiological needs in nutrients and energy for different groups of the population of Russian Federation. Moscow 2: 18-24.

28. Nedosugova LV, Nikishova MS, Volkov AK (2005) Usage of diquertin and tanaka flavonoids in complex therapy of diabetes mellitus type 2, Materials of the IX International Congress. St. Petersburg 6: 613-618.

29. Gapparov BS, Kaganov KH, Sharafetdinov MMG (2012) Organization of Therapeutic Nutrition in Health Institutions. Moscow: Dynasty 2: 208.

30. Perova NV (2005) Omega-3 polyunsaturated fatty acids in cardiology // Kardiovaskulyarnaya Terapiya i Profilaktika 21: 101-107.

31. Pogozheva AV (2004) Basics of rational diet therapy in cardiovascular diseases. Klinicheskaya Dietologiia 2: 17-29.

32. Pogozheva AV (2000) Cardiovascular diseases. Moscow 3: 320.

33. Potemkin VV, Kubatiev AA, Abramova EA (2007) Role of homocysteine in pathogenesis of vascular complications of type 2 diabetes. Problemi Endokrinologii 53: 10-12.

34. Semenova NA, Stevia- a plant of the XXI century. St. Petersburg: Dilya 20: 46.

35. Semenchenko I, Sharafetdinov Kh, Plotnikova OA, Sentsova TB (2012) Features of cytokines and hormone status in type 2 diabetes patients at alimentary exposure. Voprosy Pitaniia 81: 58-65.

36. Skripchenko ND, Sharafetdinov KhKh, Plotnikova OA, Meshcheriakova VA (2002) Influence of caloric restriction diet on clinical and biochemical parameters in patients with type 2 diabetes mellitus. Vopr Pitan 71: 13-17.

37. Skripchenko ND, Gmoshinskii IV, Mescheriakova VA (2002) Provision of selenium and lipid peroxidation parameters in patients with type 2 diabetes during dietary treatment and using of selenium-containing dietary supplement. Mikroelementi v Medicine 3: 15-19.

38. Zaslavskaya RM, Tulemisov EU, Smirnova AV, Aitmagambetova BA (2006) The vascular complications in diabetic patients. Moscow 22: 264.

39. Technical regulations of Customs Union «Safety requirements for food additives, flavours and auxiliary substances» (TP TC 029/2012).

40. Tutelyan VA, Belousov B, Gurevich KG (2007) Safety and Efficacy of Biologically Active Substances of Plant Origin. Novosibirsk: EKORKNIGA 22: 12-18.

41. Tutelyan VA, Pogozheva AV, Vysotsky VG (2008) Role of Dietary Fiber in Human Diet. Moscow: Novoe Tysiacheletie 3: 325.

42. Sharafetdinov KH, Mescheriakova VA, Plotnikova OA (2004) Effect of dietary supplement containing chromium on clinical and metabolic parameters in patients with type 2 diabetes. Voprosy Pitaniia 73: 17-20.

43. Sharafetdinov KH, Meshcheryakova VA, Plotnikova OA, Gapparov MMG (2002) Comparative evaluation of postprandial glycemia in patients with type 2 diabetes after consumption of mono- and disaccharides and sugar substitutes. Voprosy Pitaniia 71: 22-26.

44. Sharafetdinov KH, Plotnikova OA, Kulakova SN (2003) Effect of a diet enriched in monounsaturated fatty acids on clinical and metabolic parameters in patients with type 2 diabetes. Voprosy Pitaniia 72: 20-23.

45. Afridi HI, Kazi TG, Kazi N (2008) Potassium, calcium, magnesium, and sodium levels in biological samples of hypertensive and nonhypertensive diabetes mellitus patients. Biol. Trace. Elem. Res 124: 24-206.

46. American Association of Cereal Chemists (2001) The definition of dietary fiber: report of the Dietary Fiber Definition Committee to the Board of Directors of the American Association of Cereal Chemists. Cereal Foods World 46: 112-126.

47. American Diabetes Association (2008) Nutrition recommendations and interventions for diabetes A position statement of the American Diabetes Association. Diabetes Care 31: S61-S78. 
Citation: Tutelyan VA, Sharafetdinov KhKh, Plotnikova OA, Vorobiova IS, Kochetkova AA, et al. (2016) Innovative Approaches in the Development of Specialized Food Products of Optimized Composition for Patients with Type 2 Diabetes. J Diabetes Metab 7: 711. doi: $10.4172 / 2155-6156.1000711$

Page 7 of 8

48. Anderson JW, Baird P, Davis RH Jr, Ferreri S, Knudtson M, et al. (2009) Health benefits of dietary fiber. Nutr Rev 67: 188-205.

49. Archer WR, Lamarche B, St-Pierre AC (2003) High carbohydrate and high monounsaturated fatty acid diets similarly affect LDL electrophoretic characteristics in men who are losing weight. J Nutr 13: 3124-3129.

50. Babu PV, Liu D (2008) Green tea catechins and cardiovascular health: an update. Curr Med Chem 15: 1840-1850.

51. Balk EM, Tatsioni A, Lichtenstein AH, Lau J, Pittas AG (2007) Effect of chromium supplementation on glucose metabolism and lipids: a systematic review of randomized controlled trials. Diabetes Care 30: 2154-2163.

52. Brown L, Rosner B, Willett WW, Sacks FM (1999) Cholesterol-lowering effects of dietary fiber: a meta-analysis. Am J Clin Nutr 69: 30-42.

53. Butchko HH, Stargel WW, Comer CP (2002) Aspartame: Review of Safety. Regul Toxicol Pharmacol 35: S1-S93.

54. Buysschaert M, Dramais AS, Wallemacq PE, Hermans MP (2000) Hyperhomocysteinemia in type 2 diabetes: relationship to macroangiopathy, nephropathy, and insulin resistance. Diabetes Care 23: 1816-1822.

55. Carbohydrates in human nutrition (1997) Report of joint FAO/WHO export consultation. FAO Food and Nutrition Paper Rome 19: 21-28.

56. Cozma AI, Sievenpiper JL, De Souza RJ (2012) Effect of Fructose on Glycemic Control in Diabetes. A systematic review and metaanalysis of controlled feeding trials. Diabetes Care 35: 1611-1620.

57. de Boer IH, Tinker LF, Connelly S, Curb JD, Howard BV, et al. (2008) Calcium plus vitamin D supplementation and the risk of incident diabetes in the Women's Health Initiative. Diabetes Care 31: 701-707.

58. De Caterina R, Madonna R, Bertolotto A, Schmidt EB (2007) n-3 fatty acids in the treatment of diabetic patients: biological rationale and clinical data. Diabetes Care 30: 1012-1026.

59. Depeint F, Bruce WR, Shangari N, Mehta R, O'Brien PJ (2006) Mitochondrial function and toxicity: role of the B vitamin family on mitochondrial energy metabolism. Chem Biol Interact 163: 94-112.

60. Sharma A, Fakeer M (1994) Fats and oils in human nutrition. Report of a joint expert consultation. Food and Agriculture Organization of the United Nations and the World Health Organization. FAO Food Nutr Pap 57: 1-147.

61. Franz MJ, Bantle JP, Beebe CA (2002) Evidence-based nutrition principles and recommendations for the treatment and prevention of diabetes and related complications // Diabetes Care 25: 148-198.

62. Gannon MC, Nuttall JA, Damberg G (2001) Effect of protein ingestion on the glucose appearance rate in people with type 2 diabetes. J Clin Endocrinol Metab 86: 1040-1047.

63. Green C (2001) Fibre in enteral nutrition. Clin Nutr 20: 23-29.

64. Menke A, de Koning L, Shannon HS (2009) A systematic review of the evidence supporting a causal link between dietary factors and coronary heart disease. Arch Intern Med 169: 659- 669.

65. Gupta AK, Brashear MM, Johnson WD (2011) Prediabetes and prehypertension in healthy adults are associated with low vitamin D levels. Diabetes Care 34: 658-660.

66. Higdon JV, Frei B (2003) Tea catechins and polyphenols: health effects, metabolism, and antioxidant functions. Crit Rev Food Sci Nutr 43: 89-143.

67. Hodgson JM (2006) Effects of tea and tea flavonoids on endothelial function and blood pressure: a brief review. Clin Exp Pharmacol Physiol 33: 838-841.

68. Hu FB, Manson JE, Willett WC (2001) Types of dietary fat and risk of coronary heart disease: a critical review. J Am Coll Nutr 20: 5-19.

69. IFD Diabetes Atlas $6^{\text {th }}$ ed., IFD, 2013

70. Schwingshackl L, Hoffmann G (2001) Monounsaturated fatty acids, olive oil and health status: a systematic review and meta-analysis of cohort studies. Lipids Health Dis13: 154.

71. Jeppesen PB, Gregersen S, Alstrup KK, Hermansen K (2002) Stevioside induced antihyperglycaemic, insulinotropic and glucagonstatic effects in vivo studies in the diabetic Goto-Kakizaki (GK) rats Phytomedicine 9: 9-14.

72. Jeppesen PB, Gregersen S, Rolfsen SE, Jepsen M, Colombo M, et al. (2003) Antihyperglycemic and blood pressure-reducing effects of stevioside in the diabetic Goto-Kakizaki rat. Metabolism 52: 372-378.

73. Laughlin MR (2014) Normal roles for dietary fructose in carbohydrate metabolism. Nutrients 6: 3117-3129.

74. Li DM, Zhang Y, Ding B, Liu BL, Jiang LL, et al. (2013) The association between vitamin $\mathrm{D}$ deficiency and diabetic nephropathy in type 2 diabetic patients. Zhonghua Nei Ke Za Zhi 52: 970-974.

75. Livesey G, Taylor R (2008) Fructose consumption and consequences for glycation, plasma triacylglycerol, and body weight: metaanalyses and meta-regression models of intervention studies. Am J Clin Nutr 88: 1419-1437.

76. MacLean CH, Mojica WA, Morton SC (2004) Effects of omega-3 fatty acids on lipids and glycemic control in type II diabetes and the metabolic syndrome and on inflammatory bowel disease, rheumatoid arthritis, renal disease, systemic lupus erythematosus, and osteoporosis. Evid Rep Technol Assess 89: 1-4.

77. Mao S, Xiang W, Huang S, Zhang A (2014) Association between homocysteine status and the risk of nephropathy in type 2 diabetes mellitus. Clin Chim Acta 431: 206-210.

78. Shils ME (2006) Modern Nutrition in Health and Disease. Philadelphia 2: 62-82.

79. Molina M, Gonzalez R, Folgado J (2013) Correlation between plasma concentrations of homocysteine and diabetic polyneuropathy evaluated with the Semmes-Weinstein monofilament test in patients with type 2 diabetes mellitus. Med Clin (Barc) 9: 356-382.

80. Mooradian AD, Morley JE (1987) Micronutrient status in diabetes mellitus. Am J Clin Nutr 45: 877-895.

81. Mooradian AD, Failla M, Hoogwerf B, Maryniuk M, Wylie-Rosett J (1994) Selected vitamins and minerals in diabetes. Diabetes Care 17: 464-479.

82. Nagao T, Komine Y, Soga S (2005) Ingestion of a tea rich in catechins leads to a reduction in body fat and malondialdehyde-modified LDL in men. Am J Clin Nutr 81: 122-129.

83. Nuttall FQ, Gannon MC (1991) Plasma glucose and insulin response to macronutrients in nondiabetic and NIDDM subjects. Diabetes Care 14: 824-838.

84. Page G, Laight D, Cummings M (2011) Thiamine deficiency in diabetes mellitus and the impact of thiamine replacement on glucose metabolism and vascular disease. J Clin Pract 65: 684-690.

85. Peluso MR (2006) Flavonoids attenuate cardiovascular disease, inhibit phosphodiesterase, and modulate lipid homeostasis in adipose tissue and liver. Exp Biol Med 231: 1287-1299.

86. Rodriguez-Villar C, Perez-Heras A, Mercade I (2003) Comparison of a high-carbohydrate and a high-monounsaturated fat, olive oil-rich diet on the susceptibility of LDL to oxidative modification in subjects with Type 2 diabetes mellitus. Diabet Med 21: 142-149.

87. Ros E (2003) Dietary cis-monounsaturated fatty acids and metabolic control in type 2 diabetes. Am J Clin Nutr 78: 617S-625S.

88. Saw S, Yuan J, Ong C (2001) Genetic, dietary and other lifestyle determinants of plasma homocysteine concentrations in middleaged and older Chinese men and women in Singapore. Am J Clin Nutr 73: 232-239.

89. Steigman A (2003) All Dietary Fiber is fundamentally functional. Cereal Foods World 48: 128-132.

90. Tiwari S, Pratyush DD, Gupta B, Dwivedi A, Chaudhary S, et al. (2013) Prevalence and severity of vitamin D deficiency in patients with diabetic foot infection. Br J Nutr 109: 99-102.

91. Vujosevic S, Borozan S, Radojevic N, Aligrudic S, Bozovic D (2014) Relationship between 25 -hydroxyvitamin $\mathrm{D}$ and newly diagnosed type 2 diabetes mellitus in postmenopausal women with osteoporosis. Med Princ Pract 23: 229-233. 
Citation: Tutelyan VA, Sharafetdinov KhKh, Plotnikova OA, Vorobiova IS, Kochetkova AA, et al. (2016) Innovative Approaches in the Development of Specialized Food Products of Optimized Composition for Patients with Type 2 Diabetes. J Diabetes Metab 7: 711. doi: $10.4172 / 2155-6156.1000711$

Page 8 of 8

92. Whelton SP, Hyre AD, Pedersen B, Yi Y, Whelton PK, et al. (2005) Effect of dietary fiber intake on blood pressure: a meta-analysis of randomized, controlled clinical trials. J Hypertens 23: 475-481.

93. Yang G, Wu XT, Zhou Y, Wang YL (2005) Application of dietary fiber in clinical enteral nutrition: a meta-analysis of randomized controlled trials. World J Gastroenterol 11: 3935-3938.

94. Yeh GY, Eisenberg DM, Kaptchuk TJ, Phillips RS (2003) Systematic review of herbs and dietary supplements for glycemic control in diabetes. Diabetes Care 26: 1277-1294.

95. Librenti MC, Cocchi M, Orsi E, Pozza G, Micossi P (1992) Effect of soya and cellulose fibers on postprandial glycemic response in type II diabetic patients. Diabetes Care 15: 111-113.

96. Sturmer W, Kramer E, Kasper H, Schrezenmeir J (1994) Favourable glycaemic effects of a new balanced liquid diet for enteral nutrition Results of a short-term study in 30 type II diabetic patients. Clin Nutr 13: 221-227.

97. Tsai AC, Vinik AI, Lasichak A, Lo GS (1987) Effects of soy polysaccharide on postprandial plasma glucose, insulin, glucagon, pancreatic polypeptide, somatostatin, and triglyceride in obese diabetic patients. Am J Clin Nutr 45: 596-601.

98. Craig SAS, Holden JF, Auerbach MH, Frier HI (1998) Polydextrose as a soluble fiber: Physiological and analytical aspects. Cereal foods World 43 : 370-376.

99. Röytiö H, Ouwehand AC (2014) The fermentation of polydextrose in the large intestine and its beneficial effects. Benef Microbes 5: 305-313.

100. Achour L, Flourie B, Briet F, Pellier P, Marteau P, et al. (1994) Gastrointestinal effects and energy value of polydextrose in healthy nonobese men. Am J Clin Nutr 59: 1362-1368.

101. Schwab U, Louheranta A, Torronen A, Uusitupa M (2006) Impact of sugar beet pectin and polydextrose on fasting and postprandial glycemia and fasting concentrations of serum total and lipoprotein lipids in middle-aged subjects with abnormal glucose metabolism. EurJ Clin Nutr 60: $1073-1080$.
102. Stowell JD, Cho SS, Samuel P (2001) Polydextrose. In Fiber ingredients. Boca Raton: CRC Press 21: 173-201.

103. Wilson T, Luebke JL, Morcomb EF, Carrell EJ, Leveranz MC, et al. (2010) Glycemic responses to sweetened dried and raw cranberries in humans with type 2 diabetes. J Food Sci 75: H218-223.

104. Konings E, Schoffelen PF, Stegen J, Blaak EE (2014) Effect of polydextrose and soluble maize fibre on energy metabolism, metabolic profile and appetite control in overweight men and women. Br J Nutr 111: 111-121.

105. Stenman LK, Waget A, Garret C, Briand F, Burcelin R, Sulpice T, et al. (2015) Probiotic B420 and prebiotic polydextrose improve efficacy of antidiabetic drugs in mice. Diabetology \& metabolic syndrome 15: 7-75.

106. Shimomura Y, Maeda K, Nagasaki M, Matsuo Y, Murakami T, et al. (2005) Attenuated response of the serum triglyceride concentration to ingestion of a chocolate containing polydextrose and lactitol in place of sugar. BiosciBiotechnolBiochem 69: 1819-1823.

107. Pronczuk A, Hayes KC (2006) Hypocholesterolemic effect of dietary polydextrose in gerbils and humans. NutrRes 26: 27-31.

108. Ibarra A, Astbury NM, Olli K, Alhoniemi E, Tiihonen K (2016) Effect of Polydextrose on Subjective Feelings of Appetite during the Satiation and Satiety Periods: A Systematic Review and Meta-Analysis 8: 121.

109. Ibarra A, Astbury NM, Olli K, Alhoniemi E, Tiihonen K (2015) Effects of polydextrose on different levels of energy intake. A systematic review and meta-analysis. Appetite 87: 30-37.

110. Dove ER1, Mori TA, Chew GT, Barden AE, Woodman RJ, et al. (2011) Lupin and soya reduce glycaemia acutely in type 2 diabetes. Br J Nutr 106: 1045-1051.

111. Campmans-Kuijpers MJ, Sluijs I, Nothlings U, Freisling H, Overvad K, et al. (2015) The association of substituting carbohydrates with total fat and different types of fatty acids with mortality and weight change among diabetes patients. Clin Nutr 2: 1-7.

112. Wilson RF (2012) The role of genomics and biotechnology in achieving global food security for high-oleic vegetable oil. J Oleo Sci 61: 357-367. 